\title{
Knowledge and confidence level of Canadian urology residents toward biostatistics: A national survey
}

Félix Couture ${ }^{1}$; David-Dan Nguyen²; Naeem Bhojani ${ }^{3}$; Jason Y. Lee ${ }^{4}$; Patrick O.

Richard ${ }^{1}$

${ }^{1}$ Department of Surgery, Division of Urology, Centre Hospitalier Universitaire de Sherbrooke, Sherbrooke, QC, Canada; ${ }^{2}$ Faculty of Medicine, McGill University, Montreal, QC, Canada; ${ }^{3}$ Department of Surgery, Division of Urology, Centre Hospitalier de l'Université de Montréal, Montreal, QC, Canada; ${ }^{4}$ Department of Surgery, Division of Urology, University of Toronto, Toronto, ON, Canada

Cite as: Can Urol Assoc J 2020 May 12; Epub ahead of print. http://dx.doi.org/10.5489/cuaj.6495

Published online May 12, 2020

$* * *$

\section{Abstract}

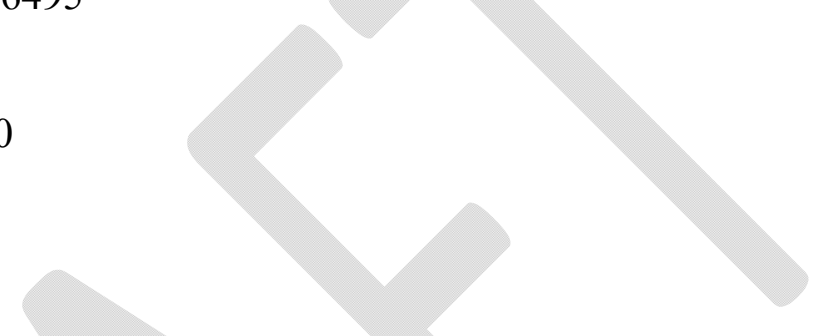

Introduction: Adequate knowledge of biostatistics is essential for healthcare providers to stay up-to-date with medical advances and maintain an evidence-based practice.

However, training in clinical research in Canadian residency programs varies considerably. Our study aimed to determine Canadian urology trainees' knowledge of biostatistics and interpretation of the scientific literature.

Methods: We conducted a national survey of all Canadian urology residents and fellows, which assessed experiences with biostatistics, self-reported confidence with statistical questions, and knowledge of biostatistical concepts.

Results: Out of 201 urology trainees, 74 (36.8\%) responded to the survey. The majority of respondents disagreed or strongly disagreed with the fact that they had sufficient training in biostatistics in medical school $(67.6 \%)$ or that their current knowledge was sufficient for the rest of their career (66.1\%). If given the chance, $82.3 \%$ of respondents would like to learn more about biostatistics. About half of respondents were able to correctly identify ordinal variables $(51.5 \%)$, discrete variables $(52.9 \%)$, or interpret adjusted odds ratios $(50.0 \%)$. Despite senior residents reporting more confidence on biostatistical questions, our results did not demonstrate significant differences in overall knowledge according to level of training or experience with biostatistics.

Conclusions: Our results identified important knowledge gaps among current Canadian urology trainees. Most trainees do not believe they have sufficient training in biostatistics. Knowledge of basic statistical concepts was lower than expected and did not significantly differ according to level of training. Our results highlight the need for 
structured, dedicated training in biostatistics for urology trainees within the new Competence by Design teaching framework.

\section{Introduction}

Adequate knowledge of statistical concepts used in medical research and in the scientific literature is essential for any good clinician. This knowledge enables providers to stay upto date with recent medical advances and maintain an evidence-based practice. However, knowledge of biostatistics remains highly variable within the medical community. (1-4) Moreover, there is currently no standardized training on biostatistical concepts across Canadian residency programs. Over the last decades, the proliferation of scientific journals has resulted in the publication of an increasing number of studies of varying methodological quality. As urology is not spared, it is imperative for any urologist to know how to critically appraise these reports and how to integrate the increasing amount of evidence into their practice in order to offer the best possible care to their patients. (5)

A report by Roth and Siemens, published in 2010, had already identified limitations in the familiarity of Canadian senior urology residents with concepts in evidence-based medicine, and an effort to improve statistical training seemed necessary. (6) Since then, a few studies from different countries and medical specialties have been able to assess residents' knowledge and confidence with biostatistics. These studies have generally demonstrated a lack of knowledge among trainees, while also recognizing the importance of good statistical knowledge. (1, 2, 7-10) No study has ever formally assessed the biostatistical knowledge of urology residents in Canada

With the introduction of the new Competence by Design (CBD) learning model, all 13 Canadian urology residency programs must adapt and incorporate new learning objectives into the clinical exposure and academic teaching of their residents. Some of these objectives include competency in clinical research and require some level of knowledge of biostatistics. However, in this era of major change in postgraduate medical education and rapidly evolving evidence-based medicine, the current level of knowledge in biostatistics and clinical research remains unknown among Canadian trainees, and there is an unmet need to assess this current state of knowledge in order to guide and adapt Canadian urology residency curricula.

Consequently, we sought to determine the comfort level and knowledge of Canadian urology residents and fellows with regard to biostatistics and the interpretation of scientific literature. We also aimed to identify factors associated with greater knowledge of biostatistics. 


\section{Methods}

Following approval from the CIUSSS de l'Estrie - CHUS Research Ethics Board, a pilot questionnaire was developed in September 2019 and tested among 20 urology residents from every training year between PGY1 and PGY5 and from 5 different programs. All items were then revised by urologists and medical educators and were adjusted according to the feedback received in the pilot survey. The survey questions were formatted as multiple choice or Likert rating scale questions. The questionnaire collected basic demographic information, assessed past experiences with biostatistics, self-reported confidence with statistical questions, and tested knowledge of general statistical concepts with a 10-question quiz (Appendix; available at cuaj.ca). Some questions were drawn from or inspired by non-validated questionnaires used in previous studies on trainees and biostatistics. (2, 8-10) Responses were anonymous and no personal information was collected. Training program and geographical information were not recorded, as it may have allowed the identification of some respondents. A web-based survey, available in English and in French, was generated on REDcap ${ }^{\mathrm{TM}}$ and distributed via email. The survey was sent to all residents and fellows currently enrolled in one of the 13 Canadian urology programs. An invitation to research and two reminders containing a link to the survey were sent out to all 201 urology trainees between October 7 and October 25, 2019. Respondents who did not complete the survey beyond the demographic and background questions were excluded.

Categorical variables were reported using proportions. Continuous variables were reported using medians (interquartile range [IQR]) or means with standard deviation, according to distribution. Chi-squared tests were used to assess differences for categorical variables, while Student's T test and analysis of variance (ANOVA) were used for continuous variables, where appropriate. Statistical analyses were conducted using IBM SPSS $^{\circledR}$ software, version 25 . All statistical tests were two-sided and p-values $<0.05$ were considered statistically significant.

\section{Results}

Out of 201 urology trainees, 74 responded to the survey (36.8\%). Six respondents were excluded because they did not complete the survey beyond the demographic and background questions. Analyses included all 68 remaining respondents.

Responses to demographic questions and previous experiences with biostatistics and research are presented in Table 1. Trainees from postgraduate year (PGY) 1-2, PGY 3-4, and $\mathrm{PGY} \geq 5$ represented $44.8 \%, 26.9 \%$, and $28.4 \%$ of the cohort, respectively. Of these, 14 respondents $(20.6 \%)$ had obtained a postgraduate degree prior to medical school, while $61.8 \%$ had completed a course of $\geq 10$ hours in epidemiology, biostatistics, or evidence-based medicine. Of the respondents, $94.1 \%$ reported having published at least one publication as an author or co-author. The majority of respondents' urology programs 
had no formal teaching in biostatistics $(58.8 \%)$, but the majority held monthly journal clubs $(66.2 \%)$.

General answers to subjective statements on comfort and experience with biostatistics are presented in Figure 1. The majority of respondents disagreed or strongly disagreed with the fact that they had sufficient training in biostatistics in medical school $(67.6 \%)$ or that their current knowledge was sufficient for the rest of their career (66.1\%). Moreover, $82.3 \%$ of respondents would like to learn more about biostatistics, if given the chance (agreed or strongly agreed), and $70.6 \%$ of respondents felt that to be a good urologist, it is essential to have a good understanding of biostatistics (agreed or strongly agreed). Data regarding perceptions on biostatistics according to PGY level are presented in Supplementary Table 1 (available in the Appendix at cuaj.ca). Respondents from PGY $\geq 5$ were more likely to agree or strongly agree with feeling comfortable designing the statistical methodology of a clinical study than PGY1-2 or PGY3-4 (36.8\% vs. 6.7\% vs. 11.1 , respectively; $p=0.02$ ). They also agreed or strongly agreed that they had sufficient knowledge of biostatistics for the rest of their career in a greater proportion than PGY1-2 and PGY3-4 (31.6\% vs. $6.7 \%$ vs. $11.1 \%$; $\mathrm{p}=0.049)$.

General results to the 10-question knowledge test are presented in Table 2. Mean average score of all respondents was $65 \%( \pm 21)$. Twenty-one respondents $(30.9 \%)$ had a score $\geq 80 \%$ on the test, while 49 respondents $(72.1 \%)$ had a score $\geq 60 \%$. Junior residents (PGY1-2) had a lower mean score $(61 \%[ \pm 21])$ than PGY3-4 $(69 \%[ \pm 18])$ or PGY $\geq 5$ $(68 \%[ \pm 23])$ residents, but that difference did not reach statistical significance $(p=0.3)$. Additional analyses also revealed a non-significant difference in mean score for PGY1 compared to $\mathrm{PGY} \geq 2(56 \%[ \pm 18]$ vs. $68 \%[ \pm 21] ; \mathrm{p}=0.056)$, but $\mathrm{PGY} 1$ were statistically less likely to have a score $\geq 80 \%$ than $P G Y \geq 2$ (6.3\% vs. $39.2 \% ; p=0.01) .61 .8 \%$ of respondents were able to correctly interpret a $\mathrm{p}$ value. Questions with a correct response rate $<60 \%$ pertained to the identification of ordinal $(51.5 \%)$ and discrete $(52.9 \%)$ variables, as well as the interpretation of adjusted odds ratios $(50.0 \%)$. Respondents from higher PGY did not perform significantly better on individual topics than more junior residents (Supplementary Table 2; available in the Appendix at cuaj.ca).

Results on the knowledge test based on self-reported perceptions on biostatistics are presented in Table 3. Respondents who agreed or strongly agreed that they were able to appraise and interpret most scientific data and articles that they encountered $(\mathrm{N}=22$; $32.4 \%)$ had better overall scores $(74 \%[ \pm 18]$ vs. $61 \%[ \pm 21] ; \mathrm{p}=0.02)$ and had scores $\geq 60 \%$ in greater proportion $(95.5 \%$ vs. $60.9 \%$; $p=0.003)$ compared to respondents who did not agree with the statement. Respondents who reported feeling comfortable designing statistical methodology for clinical research (agreed or strongly agreed; $\mathrm{N}=11$; $16.2 \%)$ also performed better $(77 \%[ \pm 14]$ vs. $63 \%[ \pm 21] ; p=0.03)$ and had scores $\geq 60 \%$ more often than their counterparts $(100 \%$ vs. 66.7\%; $\mathrm{p}=0.02)$ (Supplementary Table 3; available in the Appendix at cuaj.ca). 
We failed to identify any association between performance on the knowledge test and previous courses in biostatistics-related topics, experience with research and data analysis, number of publications, or organized training as part of the residency program (Supplementary Table 4; available in the Appendix at cuaj.ca).

\section{Discussion}

This survey provides a first look into the current level of knowledge and comfort of Canadian urology trainees toward biostatistics. Like prior studies that have also assessed statistical knowledge among trainees in non-urological specialties, our study has identified important gaps in the understanding of key statistical concepts. In our cohort, $61.8 \%$ of respondents were able to correctly interpret a $\mathrm{p}$ value, which was in line with previous surveys with a similar methodology. $(1,7,8,10)$ Only half of the trainees in our survey were able to adequately interpret odds ratios and their $95 \%$ confidence intervals, which was only slightly higher than in other studies. $(1,7,10)$ Also testifying to a critical knowledge gap among trainees, just over $50 \%$ of residents were able to correctly identify ordinal and discrete variables. Despite being consistent with the available literature, knowledge level was lower than expected regarding these basic statistical concepts, which are essential to the critical appraisal process. (11) As an exponentially increasing number of studies is becoming available, trainees will need to have a good understanding of these fundamental concepts to be equipped to appraise the literature and to be able to critically integrate new evidence into their future practice. The results from this study are therefore concerning.

Additionally, although senior trainees reported a higher degree of perceived confidence toward biostatistics than junior residents, they did not score significantly better on the 10-question test. Other studies had already shown higher level of confidence among senior residents at baseline. (12) Conversely, some studies from the United States and Europe have shown a decrease in statistical knowledge associated with years passed since graduation from medical school, where most of the evidence-based medicine training was done. $(1,10)$ We also did not identify any significant association between formal training in residency, previous teaching sessions, and performance on the knowledge test. While this lack of significant difference between groups could be due to insufficient statistical power, the fact that training level did not correlate with performance in our study may suggest that current teaching methods are insufficient to ensure statistical literacy among urology trainees.

Journal clubs appeared to be the most consistently organized activities in our sample, as $94.1 \%$ of respondents reported that their program held such structured review sessions at least every 3 months. Despite journal clubs being frequently used across residency programs, (6) their value in teaching evidence-based medicine is unclear, according to recent reviews. $(13,14)$ Structured workshops and courses on biostatistics and evidence- 
based medicine, which were reportedly organized by residency educators for only $41.2 \%$ of respondents, have been shown to be a more powerful teaching tool for residents. (1416) In prior studies, courses in evidence-based medicine and biostatistics had been associated with higher scores on knowledge tests and with more confidence toward statistics. $(7,9,12)$

All these results and the available evidence are of utmost importance given the current shift toward the CBD teaching framework and the proliferation of available scientific evidence. Within the urology CBD Canadian guidelines, there are currently two Entrustable Professional Activities (EPAs) addressing competency in clinical research. They regroup a total of 19 milestones, 8 of which address biostatistics directly or indirectly. (17) Again, the fact that previous training did not correlate with performance in our study may indicate that changes in research and statistical training are needed. This is also supported by the clear majority of trainees who reported that their current knowledge of biostatistics was insufficient for the rest of their career $(66.1 \%)$ and that they would like to learn more about biostatistics, if given the chance (82.3\%). In 2010, Roth and Siemens had identified the lack of time and lack of qualified teachers as possible barriers to the incorporation of structured evidence-based medicine teaching in residency curricula. (6) Despite these challenges, in order to fulfill the new requirements from the Royal College and ensure the competency of graduating urologists, programs will need to adjust and build strong evidence-based medicine curricula, which will likely have to include dedicated teaching sessions addressing the gaps and needs highlighted in this study.

\section{Limitations}

This study is not devoid of limitations. While adequate, the response rate of $36.8 \%$ may introduce a selection bias in our sample, as trainees interested in biostatistics or with increased biostatistical knowledge could have been more inclined to answer the survey, as may have been trainees dissatisfied with the amount of training they receive. This might cause an overestimation of the level of knowledge among trainees, as well as the overall perceived need in statistical training. The lack of differences between different groups, particularly between levels of training and previous experiences with biostatistics, may be due to insufficient statistical power from our small sample size, or to lack of granularity within study variables. The questionnaire and knowledge test used were not previously validated as a tool to discriminate biostatistics knowledge.

Nevertheless, many questions were inspired by previously published studies, which allowed for comparison, and the questionnaire was pilot-tested with 20 urology residents from PGY1-5 prior to distribution. Finally, respondents filled the knowledge test in a non-controlled setting, which may have allowed respondents to answer questions with the help of other resources. However, the anonymous and voluntary nature of the survey makes it unlikely that respondents would cheat on the knowledge test. 


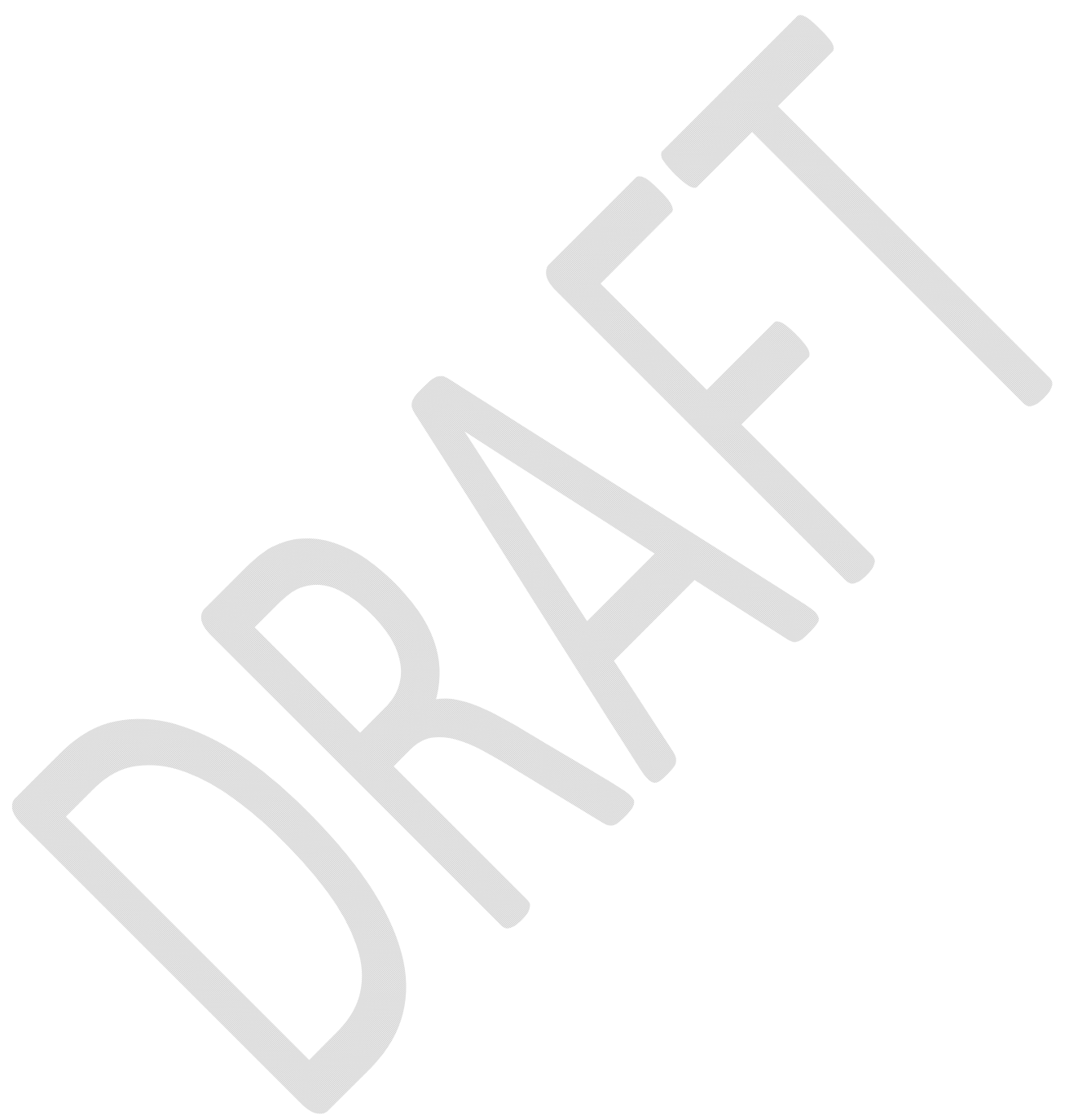




\section{Conclusions}

Our results provide important insight into the knowledge and comfort level of Canadian urology trainees toward biostatistics, identifying important gaps in knowledge. The majority of current trainees did not believe they have sufficient training in biostatistics. Knowledge of some basic statistical concepts, including the identification of variables and interpretation of odds ratios, was lower than expected. Knowledge did not significantly improve with level of training. As Canadian postgraduate urology education shifts toward the CBD framework and an exponentially amount of medical literature becomes available, our results highlight the need for structured training in biostatistics within this new teaching model. 


\section{References}

1. Windish DM, Huot SJ, Green ML. Medicine residents' understanding of the biostatistics and results in the medical literature. JAMA. 2007;298(9):1010-22.

2. Susarla SM, Lifchez SD, Losee J, Hultman CS, Redett RJ. Plastic Surgery Residents' Understanding and Attitudes Toward Biostatistics: A National Survey. Ann Plast Surg. 2016;77(2):231-6.

3. Gore A, Kadam Y, Chavan P, Dhumale G. Application of biostatistics in research by teaching faculty and final-year postgraduate students in colleges of modern medicine: A cross-sectional study. Int J Appl Basic Med Res. 2012;2(1):11-6.

4. Polychronopoulou A, Eliades T, Taoufik K, Papadopoulos MA, Athanasiou AE. Knowledge of European orthodontic postgraduate students on biostatistics. Eur J Orthod. 2011;33(4):434-40.

5. Han JL, Gandhi S, Bockoven CG, Narayan VM, Dahm P. The landscape of systematic reviews in urology (1998 to 2015): an assessment of methodological quality. BJU Int. 2017;119(4):638-49.

6. Roth K, Siemens DR. The status of evidence-based medicine education in urology residency. Can Urol Assoc J. 2010;4(2):114-20.

7. Araoye I, He JK, Gilchrist S, Stubbs T, McGwin G, Jr., Ponce BA, et al. A National Survey of Orthopaedic Residents Identifies Deficiencies in the Understanding of Medical Statistics. J Bone Joint Surg Am. 2019.

8. Best AM, Laskin DM. Oral and maxillofacial surgery residents have poor understanding of biostatistics. J Oral Maxillofac Surg. 2013;71(1):227-34.

9. Alzahrani SH, Aba Al-Khail BA. Resident physician's knowledge and attitudes toward biostatistics and research methods concepts. Saudi Med J. 2015;36(10):1236-40.

10. Msaouel P, Kappos T, Tasoulis A, Apostolopoulos AP, Lekkas I, Tripodaki ES, et al. Assessment of cognitive biases and biostatistics knowledge of medical residents: a multicenter, cross-sectional questionnaire study. Med Educ Online. 2014;19:23646.

11. Scales CD, Jr., Peterson B, Dahm P. Interpreting statistics in the urological literature. J Urol. 2006;176(5):1938-45.

12. Keddis MT, Beckman TJ, Cullen MW, Reed DA, Halvorsen AJ, Wittich CM, et al. Senior internal medicine residents' confidence with essential topics in evidence-based medicine taught during internship. J Grad Med Educ. 2011;3(4):490-6.

13. Ilic D, de Voogt A, Oldroyd J. The use of journal clubs to teach evidence-based medicine to health professionals: A systematic review and meta-analysis. J Evid Based Med. 2020.

14. Larsen CM, Terkelsen AS, Carlsen AF, Kristensen HK. Methods for teaching evidence-based practice: a scoping review. BMC Med Educ. 2019;19(1):259.

15. Ahmadi N, McKenzie ME, Maclean A, Brown CJ, Mastracci T, McLeod RS, et al. Teaching evidence based medicine to surgery residents-is journal club the best format? A systematic review of the literature. J Surg Educ. 2012;69(1):91-100. 
16. Barreto JN, Piche SL, Hogan BM, Barreto EF. Effect of a multimodal multidisciplinary training program on pharmacy residents' knowledge and confidence toward research and biostatistics. Curr Pharm Teach Learn. 2020;12(1):20-6.

17. Royal College of Physicians and Surgeons of Canada. MAINPORT ePortfolio [Limited Access] [updated January 2020]. 
Figures and Tables

Fig. 1. General ratings from subjective statements on biostatistical questions $(n=68)$.

\section{$\square$ Strongly agree $\square$ Agree $\square$ Neutral $\square$ Disagree $\square$ Strongly disagree}

I have had sufficient training in biostatistics in medical school

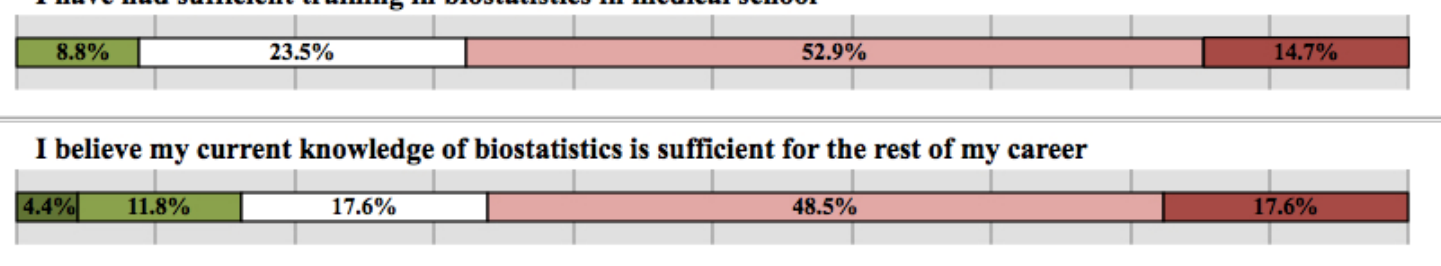

I am able to appraise and interpret most scientific data and articles that I encounter

\begin{tabular}{|l|l|l|l|l|l|l|}
\hline $\mathbf{2 7 . 9} \%$ & $\mathbf{3 6 . 8} \%$ & $27.9 \%$ & $2.9 \%$ \\
\hline
\end{tabular}

I feel confident determining if the appropriate statistical procedure was used in research

\begin{tabular}{|ll|l|l|l|l|l|}
\hline $2.9 \%$ & $11.8 \%$ & $19.1 \%$ & & & \\
& & & & \\
\hline
\end{tabular}

I feel confident interpreting a $P$ value for a given result

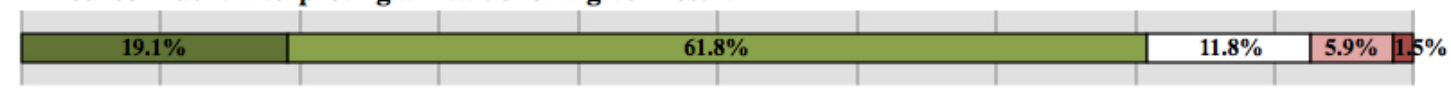

I would feel comfortable designing the statistical methodology for a given clinical study

\begin{tabular}{|ll|l|l|l|l|}
\hline $1.5 \%$ & $14.7 \%$ & $23.5 \%$ & $32.4 \%$ & $27.9 \%$ \\
\hline
\end{tabular}

Given the chance, I would like to learn more about biostatistics

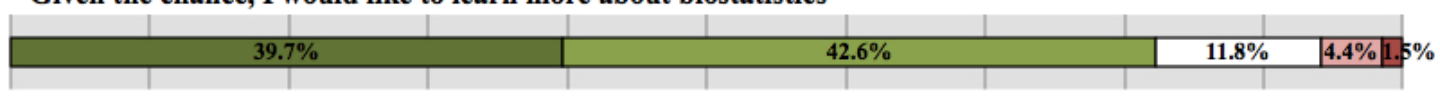

To be a good urologist, it is essential to have a good understanding of biostatistics

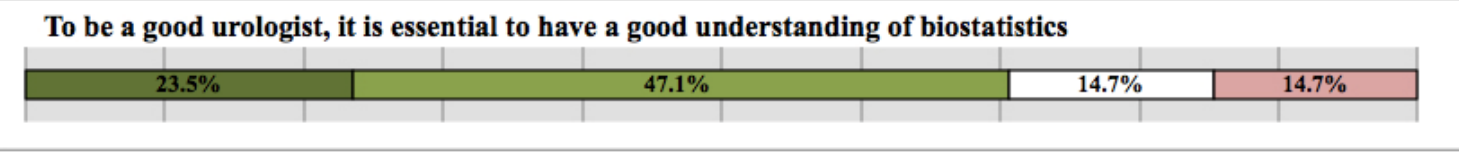




\begin{tabular}{|c|c|c|c|}
\hline \multicolumn{3}{|l|}{ Variable } & Value \\
\hline Age (median, IQR) & & $28(26-30)$ \\
\hline \multirow{3}{*}{$\begin{array}{l}\text { Post-graduate Year } \\
\mathrm{N}(\%) \\
(1 \text { missing value })\end{array}$} & \multicolumn{2}{|l|}{ PGY1-2 } & $30(44.8)$ \\
\hline & \multicolumn{2}{|l|}{ PGY3-4 } & $18(26.9)$ \\
\hline & \multicolumn{2}{|l|}{$\mathrm{PGY} \geq 5$} & $19(28.4)$ \\
\hline \multirow{4}{*}{$\begin{array}{l}\text { Highest level of } \\
\text { schooling prior to } \\
\text { medical school } \\
\mathrm{N}(\%) \\
\text { (1 missing value) }\end{array}$} & \multicolumn{2}{|c|}{ College/CEGEP } & $22(32.4)$ \\
\hline & \multicolumn{2}{|c|}{ Post-secondary degree } & $27(39.7)$ \\
\hline & \multicolumn{2}{|c|}{ Post-graduate degree } & $14(20.6)$ \\
\hline & \multicolumn{2}{|c|}{ Degree in professional field } & $4(5.8)$ \\
\hline \multirow{4}{*}{$\begin{array}{l}\text { Has taken a post- } \\
\text { secondary course in: } \\
\mathrm{N}(\%)\end{array}$} & \multicolumn{2}{|l|}{ Epidemiology } & $26(38.2)$ \\
\hline & \multicolumn{2}{|l|}{ Biostatistics } & $31(45.6)$ \\
\hline & \multicolumn{2}{|c|}{ Evidence-based medicine } & $19(27.9)$ \\
\hline & \multicolumn{2}{|c|}{ Any of these three topics } & $42(61.8)$ \\
\hline \multicolumn{3}{|c|}{ Currently involved in clinical research N (\%) } & $50(73.5)$ \\
\hline \multicolumn{3}{|c|}{ Had previously performed data analysis N (\%) } & $45(66.2)$ \\
\hline \multirow{4}{*}{$\begin{array}{l}\text { Number of publications } \\
\mathrm{N}(\%)\end{array}$} & \multicolumn{2}{|c|}{ None } & $4(5.9)$ \\
\hline & \multicolumn{2}{|l|}{$1-2$} & $33(48.5)$ \\
\hline & \multicolumn{2}{|l|}{$3-9$} & $22(32.3)$ \\
\hline & \multicolumn{2}{|l|}{10 or more } & $9(13.2)$ \\
\hline \multirow{11}{*}{$\begin{array}{l}\text { Training in residency } \\
\text { program } \\
\mathrm{N}(\%)\end{array}$} & \multirow{3}{*}{$\begin{array}{l}\text { Formal } \\
\text { teaching in } \\
\text { biostatistics }\end{array}$} & None & $40(58.8)$ \\
\hline & & $1-5 \mathrm{~h} /$ year & $23(33.8)$ \\
\hline & & $>5 \mathrm{~h} /$ year & $5(7.4)$ \\
\hline & \multirow{4}{*}{ Journal clubs } & $0-4$ times/year & $4(5.9)$ \\
\hline & & q2-3 months & $15(22.0)$ \\
\hline & & qmonth & $45(66.2)$ \\
\hline & & qweek & $4(5.9)$ \\
\hline & \multirow{4}{*}{$\begin{array}{l}\text { Dedicated } \\
\text { research } \\
\text { electives } \\
\text { (1 missing } \\
\text { value) }\end{array}$} & None & $23(34.3)$ \\
\hline & & $<4$ weeks & $7(10.4)$ \\
\hline & & 4-8 weeks & $13(19.4)$ \\
\hline & & $>8$ weeks & $24(35.8)$ \\
\hline
\end{tabular}

IQR: Interquartile range; PGY: Postgraduate year 


\begin{tabular}{|c|c|c|c|}
\hline \multicolumn{4}{|l|}{ General results based on PGY } \\
\hline Variable & PGY & $\begin{array}{c}\text { Mean score } \\
(\%)\end{array}$ & $\mathbf{p}$ \\
\hline \multirow{4}{*}{ Mean average score $(\%)$} & All & $65.0 \pm 20.7$ & \multirow{4}{*}{0.3} \\
\hline & PGY1-2 & $60.7 \pm 21.0$ & \\
\hline & PGY3-4 & $68.9 \pm 17.8$ & \\
\hline & $\mathrm{PGY} \geq 5$ & $67.9 \pm 23.0$ & \\
\hline \multirow{4}{*}{$\begin{array}{l}\text { Score } \geq 80 \% \\
\mathrm{n}(\%)\end{array}$} & All & $21(30.9)$ & \multirow{4}{*}{0.5} \\
\hline & PGY1-2 & $8(26.7)$ & \\
\hline & PGY3-4 & $5(27.8)$ & \\
\hline & $\mathrm{PGY} \geq 5$ & $8(42.1)$ & \\
\hline \multirow{4}{*}{$\begin{array}{l}\text { Score } \geq 60 \% \\
\mathrm{n}(\%)\end{array}$} & All & $49(72.1)$ & \multirow{4}{*}{0.15} \\
\hline & PGY1-2 & $19(63.3)$ & \\
\hline & PGY3-4 & $16(88.9)$ & \\
\hline & $P G Y \geq 5$ & $13(68.4)$ & \\
\hline \multicolumn{4}{|c|}{ Correct response rates to individual question topics } \\
\hline \multicolumn{2}{|l|}{ Individual question topics } & \multicolumn{2}{|c|}{$\begin{array}{c}\text { Correct answer } \\
\text { n }(\%)\end{array}$} \\
\hline \multicolumn{2}{|l|}{ Identifying continuous variables } & \multicolumn{2}{|c|}{$61(89.7)$} \\
\hline \multicolumn{2}{|l|}{ Identifying ordinal variables } & \multicolumn{2}{|c|}{$35(51.5)$} \\
\hline \multicolumn{2}{|l|}{ Identifying discrete variables } & \multicolumn{2}{|c|}{$36(52.9)$} \\
\hline \multicolumn{2}{|c|}{ Identifying correct statistical test (Student's) } & \multicolumn{2}{|c|}{$44(64.7)$} \\
\hline \multicolumn{2}{|c|}{ Identifying correct study type (case-control) } & \multicolumn{2}{|c|}{$41(60.3)$} \\
\hline \multicolumn{2}{|c|}{ Stating the purpose of blinding in clinical research } & \multicolumn{2}{|c|}{$58(85.3)$} \\
\hline \multicolumn{2}{|l|}{ Defining of a Type I error } & \multicolumn{2}{|c|}{$48(70.6)$} \\
\hline \multicolumn{2}{|l|}{ Defining of a $p$ value } & \multicolumn{2}{|c|}{$42(61.8)$} \\
\hline \multicolumn{2}{|c|}{ Calculating and defining a relative risk } & \multicolumn{2}{|c|}{$43(63.2)$} \\
\hline \multicolumn{2}{|l|}{ Interpreting adjusted odds ratios } & \multicolumn{2}{|c|}{$34(50.0)$} \\
\hline
\end{tabular}

PGY: Postgraduate year 


\begin{tabular}{|c|c|c|c|}
\hline Subjective statement & Perception & $\begin{array}{c}\text { Mean score } \\
(\%)\end{array}$ & $\mathbf{p}$ \\
\hline \multirow{2}{*}{$\begin{array}{l}\text { Had sufficient training in } \\
\text { medical school }\end{array}$} & Strongly agree or agree & $68.3 \pm 14.7$ & \multirow{2}{*}{0.7} \\
\hline & Others & $64.7 \pm 21.2$ & \\
\hline \multirow{2}{*}{$\begin{array}{l}\text { Has sufficient knowledge for } \\
\text { rest of career }\end{array}$} & Strongly agree or agree & $72.7 \pm 21.5$ & \multirow{2}{*}{0.18} \\
\hline & Others & $63.5 \pm 20.4$ & \\
\hline \multirow{2}{*}{$\begin{array}{l}\text { Is able to appraise most data } \\
\text { and articles }\end{array}$} & Strongly agree or agree & $73.6 \pm 17.6$ & \multirow{2}{*}{0.02} \\
\hline & Others & $60.9 \pm 21.0$ & \\
\hline \multirow{2}{*}{$\begin{array}{l}\text { Is able to determine } \\
\text { appropriate statistical test }\end{array}$} & Strongly agree or agree & $74.0 \pm 21.7$ & \multirow{2}{*}{0.14} \\
\hline & Others & $63.4 \pm 20.3$ & \\
\hline \multirow{2}{*}{$\begin{array}{l}\text { Is confident interpreting } \\
\mathrm{p} \text { value }\end{array}$} & Strongly agree or agree & $66.5 \pm 19.9$ & \multirow{2}{*}{0.2} \\
\hline & Others & $58.5 \pm 23.4$ & \\
\hline \multirow{2}{*}{$\begin{array}{l}\text { Is comfortable designing } \\
\text { statistics methodology }\end{array}$} & Strongly agree or agree & $77.3 \pm 13.5$ & \multirow{2}{*}{0.03} \\
\hline & Others & $62.6 \pm 21.1$ & \\
\hline \multirow{2}{*}{$\begin{array}{l}\text { Would like to learn more on } \\
\text { biostatistics }\end{array}$} & Strongly agree or agree & $70.8 \pm 18.3$ & \multirow{2}{*}{0.29} \\
\hline & Others & $63.8 \pm 21.1$ & \\
\hline \multirow{2}{*}{$\begin{array}{l}\text { Believes biostatistics is } \\
\text { essential for urologists }\end{array}$} & Strongly agree or agree & $65.0 \pm 20.5$ & \multirow{2}{*}{1.00} \\
\hline & Others & $65.0 \pm 21.6$ & \\
\hline
\end{tabular}

